\title{
PERAMALAN ARUS LALU LINTAS BERDASARKAN WAKTU TEMPUH DAN CUACA MENGGUNAKAN METODE TIME SERIES DECOMPOSITION
}

\author{
Muhammad Hudzaifah', Ali Akbar Rismayadi ${ }^{2}$ \\ 1 Universitas Adhirajasa Reswara Sanjaya \\ e-mail: hudzaifah175@gmail.com \\ 2Universitas Adhirajasa Reswara Sanjaya \\ e-mail: ali@ars.ac.id
}

\begin{abstract}
Abstrak
Prediksi lalu lintas telah menjadi tren topik penelitian untuk pengembangan transportasi cerdas. Permasalahan lalu lintas pada setiap negara khususnya negara berkembang permasalahan masyarakat umum yang terjadi yaitu tidak dapat memprediksi kondisi lalu lintas di masa yang akan datang. Kondisi lalu lintas pada waktu tertentu berbeda dengan kondisi lalu lintas pada saat yang berbeda karena kebiasaan masyarakat yang berbeda pada setiap waktunya. Kondisi lalu lintas juga dipengaruhi oleh kondisi cuaca pada saat itu. Dengan mengolah data arus lalu lintas yang dijadikan faktor untuk menganalisa kondisi lalu lintas. Prediksi lalu lintas yang akurat dan efektif akan memberikan informasi arus lalu lintas sesuai kepada pengguna jalan dan efektif dalam memecahkan kepadatan arus lalu lintas. Pada penelitian ini penulis mengusulkan metode Time series decomposition guna melakukan prediksi lalu lintas. Metode time series decomposition adalah metode peramalan dengan menggunakan analisa pola hubungan antara variable yang akan diperkirakan dengan variabel waktu. Secara umum time series mengalisa 4 pola data yaitu pola trend, seasonal, pola horizontal dan pola siklis. Data yang hitung pada penelitian yaitu data waktu tempuh perjalan dan kondisi cuaca. Metode prediksi time series decomposition diterapkan pada pada aplikasi mobile berbasis android agar pengguna dapat mengetahui informasi prediksi melalui smartphone. Hasil dari penelitian ini menghasilkan prediksi dengan nilai error RMSE sebesar 3.80\%. Hasil tersebut membuktikan bahwa metode time series decomposition dapat digunakan untuk membantu prediksi lalu lintas.
\end{abstract}

Kata Kunci: Prediksi, Lalu Lintas, Time series Decomposition, Android

\begin{abstract}
Traffic prediction has become a trend of research topics for the development of intelligent transportation. Traffic problems in each country, especially developing countries, are common problems that occur, which cannot predict traffic conditions in the future. Traffic conditions at certain times differ from traffic conditions at different times due to different community habits at all times. Traffic conditions were also affected by weather conditions at that time. By processing traffic flow data which is used as a factor to analyze traffic conditions. Accurate and effective traffic prediction will provide traffic information that is appropriate to road users and effective in solving traffic flow densities. In this study the authors propose a Time series decomposition method to predict traffic. The method of time series decomposition is a forecasting method by using a pattern analysis of the relationship between variables that will be estimated with time variables. In general, time series analyzes 4 data patterns, namely trend, seasonal, horizontal patterns and cyclical patterns. The data calculated in the study are travel time data and weather conditions. The time series decomposition prediction method is applied to an Android-based mobile application so that users can find out predictive information via a smartphone. The results of this study produce predictions with an RMSE error value of $3.80 \%$. These results prove that the time series decomposition method can be used to help predict traffic.
\end{abstract}

Keywords: Prediction, Traffic, Time series Decomposition, Android. 


\section{Pendahuluan}

Peramalan atau forecasting merupakan perkiraan mengenai sesuatu yang belum terjadi. Peramalan juga didefinisikan sebagai seni atau ilmu untuk memperkirakan kejadian dimasa depan(Hidayah et al., 2017). Prediksi atau ramalan merupakan kegiatan yang dilakukan oleh peneliti dalam memperkirakan kejadian dimasa yang akan datang dengan menggunakan pendekatan tertentu (Virrayyani \& Sutikno, 2016).

Peramalan merupakan salah satu unsur penting dalam mengambil keputusan, sebab efektif atau tidaknya suatu keputusan umumnya tergantung dari beberapa faktor yang tidak dapat kita lihat pada saat keputusaan diambil. (Hidayah et al., 2017).

Permasalahan arus lalu lintas di perkotaan merupakan suatu permasalahan yang kompleks, satu permasalahan dapat di selesaikan, akan muncul permasalahan berikutnya, bisa disebakan oleh, padatnya jumlah penduduk, volume kendaraan, dan tentunya kurangnya sarana jalan yang memadai, oleh karena itu akan berdampak pada waktu tempuh dari setiap perjalan yang di lewati (Julianto, 2010).

Memprediksi waktu tempuh yang akurat ke suatu tempat, dapat juga di pengaruhi oleh keadaaan cuaca serta kondisi lalu lintas dengan tingkat kemacetan yang bervariasi (Mardiati, 2014).

Time series Decompostion atau runtun waktu adalah himpunan observasi data terurut dalam waktu. Metode time series adalah metode peramalan dengan menggunakan analisa pola hubungan antara variable yang akan diperkirakan dengan variable waktu (Metisen \& Sari, 2015). Secara umum terdapat 4 pola data time series yaitu pola trend, pola seasonal, pola horizontal dan pola siklus (Aghnaita, 2016).

Pada penelitian sebelumnya digunakan untuk melakukan simulasi peramalan perkembangan akademik mahasiswa (Ashari, 2012). membuktikan bahwa metode time series memberikan prediksi yang cukup akurat.

Penggunaan Android sebagai system operasi yang mendukung dalam penerapan metode ini tidak lain adalah, berdasarkan keberhasilan android sebagai sistem operasi yang popular dan mampu mengerjakan berbagai pekerjaan yang sifatnya kecerdaan buatan (Safaat, 2012).

\section{Metode Penelitian}

Langkah - Ingkah pengumpulan data sangat penting dalam pembuatan skripsi ini, maka teknik pengumpulan data yang penulis digunakan adalah sebagai berikut :

1. Observasi

Pada teknik ini pengumpulan data dengan cara pengamatan langsung dan melakukan pencatatan terhadap data yang dibutuhkan. Penulis melakukan observasi langsung dengan melakukan melakukan perjalanan dibeberapa waktu berbeda.

2. Wawancara

Penulis melakukan wawancara kepada masyarakat untuk menganalisa kepadatan lalu lintas pada waktu tertentu.

3. Studi Pustaka

Penulis mengumpulkan data dari sumber buku, jurnal dan referensi lainya dari internet yang berhubungan dengan penelitian agar menghasilkan penilitian yang baik sebagai bahan tambahan dalam aplikasi prediksi lalu lintas.

Waterfall

Metode pengembangan aplikasi yang dibutukan penulis dalam penelitian ini adalah metode Waterfall. Metode Waterfall sering disebut dengan alur hidup klasik. Metode ini dapat menyediakan alur hidup perangkat lunak secara sekuensional atau terurut mulai dari analisi, desain, pengkodean, pengujian, dan tahap pendukung.

a. Analisis Kebutuhan.

Proses ini dilakukan secara sungguhsungguh untuk mengkhususkan kebutuhan perangkat lunak agar bisa dipahami perangkat lunak seperti apa yang dibutuhan oleh pengguna

b. Desain

Pada tahap ini mentranslasi kebutuhan perangkat lunak mulai dari analisi kebutuhan ke repersentasi desain agar dapat diimplementasikan menjadi program pada tahap berikutnya.

c. Pembuatan kode program

Pada tahap ini penulis menggunakan metode Time series sebagai perhitungan algoritma dan bahasa pemrogram Java.

d. Pengujian

Pada tahap ini pengujian digunakan untuk meminimalisir kesalahan dan dapat memastikan output yang dihasilkan sesuai dengan yang diinginkan. 


\section{Data Mining}

Data Mining adalah suatu istilah yang digunakan untuk menentukan pengetahuan yang tersembunyi didalam data base. Data mining merupakan proses semi otomatik yang menggunakan teknik statistik, matematika, keceradasan buatan dan machine learning untuk mengekstrasi dan mengindentifikasi informasi pengentahuan yang terkait dari berbagai data base besar (Apostolakis, 2010).

Data mining dibagi menjadi beberapa kelompok berdasarkan tugas yang dapat dilakukan, yaitu :

1. Deskripsi

Mencari cara menggambarkan pola dan kecenderungan yang terdapat dalam data.

2. Klasifikasi

Dalam klasifikasi, terdapat target variable ketegori, sebagai contoh, penggolongan pendapatan dapat dipisahkan dalam tiga ketegori, yaitu pendapatan tinggi, pendapatan sedang dan pendapatan rendah.

3. Estimasi

Dalam Estimasi, target variable berbentuk numerik tidak berbentuk ketegori. Model dibangun dengan menggunakan record lengkap yang menyediakan nilai dari variable prediksi.

4. Prediksi

Prediksi hampir sama dengan klasifikasi dan estimasi, kecuali bahwa dalam prediksi nilai dari hasil akan ada dimasa mendatang.

5. Pengklusteran

Merupakan pengelompokan record pengamatan atau memperhatikan dan membentuk kelas objek-objek yang memiliki kemiripan satu dengan yang lainya dan memiliki ketidakmiripan denan record-record dalam kluster lain.

6. Asosiasi

Dalam data mining asosiasi adalah menentukan atribut yang muncul dalam satu waktu.

\section{Time series}

Analisis Time series merupakan metode peramalan kuantatif untuk menentukan pola data masa lampau yang dikumpulkan berdasarkan urutan waktu, yang disebut data time series. Suatu data time series dapat dilihat sebagai suatu representasi dari realisasi suatu variable random yang biasa mempunyai interval waktu yang sama san diamati pada periode tertentu.

Data time series ini merupakan suatu deskripsi lampau dan digunakan untuk meramalkan masa depan. Dalam membuat prediksi dengan asumsi bahwa masa depan merupakan fungsi dari masa lalu dengan kata lain apa terjadi di selama kurun waktu tertentu dan menggunakan data masa lalu tersebut untuk melakukan peramalan. Tipe data time series menurut berbagai jenis adalah (Ryan \& Wijanarto, 2018).

a. Trend adalah pola data yang terjadi pada saat terdapat kenaikan atau penurunan sekuler jangka panjang dalam data

b. Musiman (Seasonal) adalah pola data yang terjadi di perngaruhi oleh faktor musiman.

c. Pola Siklis adalah pola data yang terjadi jika data dipengaruhi oleh fluktuasi ekonomi jangka panjang seperti yang berhubungan dengan bisnis.

\section{Metode Decomposition}

Metode dekomposisi adalah salah metode peramalan yang didasarkan dengan pada kenyataan bahwa biasanya apa yang terjadi akan berulang atau kembali pada pola yang sama. Artinya yang dulu selalu naik pada watu yang akan datang akan naik juga yang biasa berkurang akan berkurang juga, yang biasanya fluktuasi akan fluktuasi juga dan yang biasanya tidak teratur maka akan teratur(Fitria et al., 2016).

Perubahan suatu hal itu biasanya mempunyai pola yang kompleks, misalnya ada suatu unsur yang mengalami kenaikan, berfluktuasi, dan tidak teratur. Untuk melakukan analisis dan meramalkan umumnya sangat sulit, sehingga biasanya diadakan dekomposisi (pemecahan) kedalam 3 komponen, yakni: trend, fluktuasi musiman, , dan perubahan-perubahan yang bersifat random (Aghnaita, 2016).

Masing masing komponen akan dicari besar nilainya dan digabungkan menjadi nilai taksiran dan ramalan dengan persamaan :

$$
X=T x M x S x R
$$

Dimana :

$X=$ forecast

$\mathrm{T}=$ Trend

$M=$ Fluktuasi musiman, 
$\mathrm{S}=$ Fluktuasi Siklis

$\mathrm{R}=$ Fluktuasi Random.

\section{Mencari Nilai Trend}

Jika $\mathrm{m}$ adalah bilangan genap, nilai trend - cycle component T_t menggunakan 2 m-MA (Moving Average). Jika $\mathrm{m}$ adalah ganjil , nilai trend - cycle component T_t menggunakan m - MA. Rumus MA (Moving Average) adalah :

$T_{t}=\frac{1}{m} \sum_{j=-k}^{k} y_{t+j}$

2. Mencari Nilai Musiman (Seasonal)

Untuk memperkirakan komponen musiman untuk setiap musim, cukup ratarata nilai yang ditentukan untuk musim itu. Misalnya, dengan data bulanan, komponen musiman untuk Maret adalah rata-rata dari semua nilai Maret yang didepresi dalam data.

Nilai-nilai komponen musiman ini kemudian disesuaikan untuk memastikan bahwa mereka menambahkan ke nol. Komponen musiman diperoleh dengan merangkai nilai-nilai bulanan ini, dan kemudian mereplikasi urutan untuk setiap tahun data. Untuk memberikan S_t

\section{Mencari Nilai Random (Remainder)}

Komponen Remainder bisa dihitung dengan mengurangi komponen musiman dan trend.

\section{RMSE (Root Mean Square Error)}

RMSE adalah metode alternatif untuk mengevaluasi teknik peramalan yang digunakan untuk mengukur tingkat akurasi hasil prakiraan suatu model. RMSE merupakan nilai rata-rata dari jumlah kuadrat kesalahan, juga dapat menyatakan ukuran besarnya kesalahan yang dihasilkan oleh suatu model prakiraan. Nilai RMSE rendah menunjukkan bahwa variasi nilai yang dihasilkan oleh suatu model prakiraan mendekati variasi nilai obeservasinya.

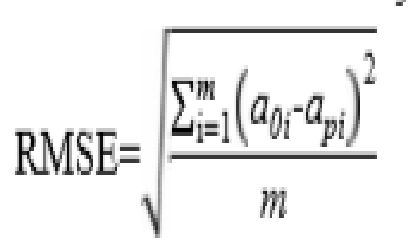

Dimana :

a0 adalah nilai data observasi ke-i ap adalah nilai data prediksi ke-i $\mathrm{m}$ adalah jumlah data

\section{Hasil dan Pembahasan}

3.1 Data Time series

Tabel 1. Data Kondisi Cuaca dan Waktu Tempuh

\begin{tabular}{|c|c|c|}
\hline Jam & $\begin{array}{c}\text { Kondisi } \\
\text { Cuaca }\end{array}$ & Waktu tempuh \\
\hline $1: 00$ & Cerah & 21 Menit \\
\hline $2: 00$ & Cerah & 21 Menit \\
\hline $3: 00$ & Cerah & 21 Menit \\
\hline $4: 00$ & Cerah & 21 Menit \\
\hline $5: 00$ & Cerah & 25 Menit \\
\hline $6: 00$ & Cerah & 29 Menit \\
\hline $7: 00$ & Cerah & 28 Menit \\
\hline $8: 00$ & Cerah & 36 Menit \\
\hline $9: 00$ & Cerah & 39 Menit \\
\hline $10: 00$ & Cerah & 33 Menit \\
\hline $11: 00$ & Cerah & 32 Menit \\
\hline $12: 00$ & Cerah & 31 Menit \\
\hline $13: 00$ & Cerah & 29 Menit \\
\hline $14: 00$ & Cerah & 29 Menit \\
\hline $15: 00$ & Cerah & 28 Menit \\
\hline $16: 00$ & Cerah & 34 Menit \\
\hline $17: 00$ & Cerah & 32 Menit \\
\hline $18: 00$ & Cerah & 35 Menit \\
\hline $19: 00$ & Cerah & 34 Menit \\
\hline $20: 00$ & Cerah & 34 Menit \\
\hline $21: 00$ & Cerah & 28 Menit \\
\hline $22: 00$ & Cerah & 25 Menit \\
\hline $23: 00$ & Cerah & 21 Menit \\
\hline $24: 00$ & Cerah & 27 Menit \\
\hline
\end{tabular}

\subsection{Rancangan Algoritma}

Berikut flowchart dari rancangan algoritma Time series: 


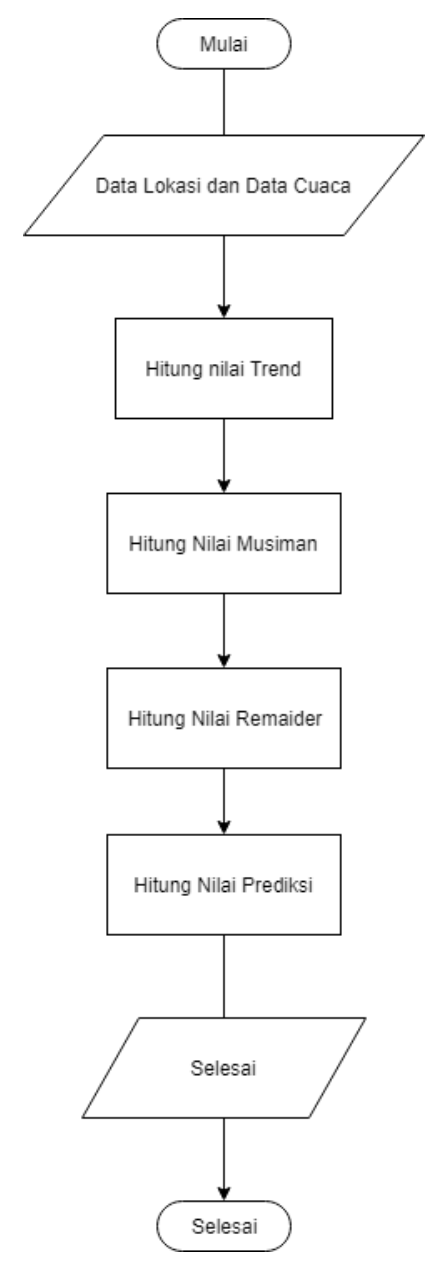

Gambar 1. Flowchart Time series

\section{Menghitung Nilai Trend}

$$
T_{t}=\frac{1}{m} \sum_{j=-k}^{k} y_{t+j}
$$

Jika $m=24$, maka $=11 \mathrm{j}=-12$

$$
\begin{aligned}
& T_{t}=\frac{1}{24}(693) \\
& T_{t}=\frac{693}{24} \\
& T_{t}=28.875
\end{aligned}
$$

\section{Menghitung Nilai Detrend}

Det $=21-28.875$

Det $=-7.875$

\section{Menghitung Nilai Seasonal}

$$
\begin{gathered}
(7.20)+(-7.24)+(-8.52)+(-6.35)+ \\
(-5.52)+(-11.18)
\end{gathered}
$$

$=-7.67$

\begin{tabular}{|c|c|c|c|c|}
\hline Waktu & $\begin{array}{l}\text { Nilai } \\
\text { Trend }\end{array}$ & $\begin{array}{l}\text { Nilai } \\
\text { De Trended }\end{array}$ & $\begin{array}{l}\text { Nilai } \\
\text { Seasonal }\end{array}$ & $\begin{array}{l}\text { Nilai } \\
\text { Remainder }\end{array}$ \\
\hline $1: 00$ & $\begin{array}{c}28.8 \\
7\end{array}$ & -7.87 & -7.67 & -0.20 \\
\hline $2: 00$ & $\begin{array}{c}28.8 \\
7 \\
\end{array}$ & -7.87 & -8.40 & 0.53 \\
\hline $3: 00$ & $\begin{array}{c}28.8 \\
7\end{array}$ & -7.87 & -8.31 & 0.44 \\
\hline $4: 00$ & $\begin{array}{c}28.8 \\
7\end{array}$ & -7.87 & -7.36 & -0.51 \\
\hline $5: 00$ & $\begin{array}{c}28.8 \\
7\end{array}$ & -3.87 & -7.18 & 3.31 \\
\hline $6: 00$ & $\begin{array}{c}28.8 \\
7\end{array}$ & 0.12 & -1.54 & 1.67 \\
\hline $7: 00$ & $\begin{array}{c}28.8 \\
7\end{array}$ & -0.87 & -1.27 & 0.40 \\
\hline $8: 00$ & $\begin{array}{c}28.8 \\
7\end{array}$ & 7.12 & 0.17 & 6.95 \\
\hline $9: 00$ & $\begin{array}{c}28.8 \\
7\end{array}$ & 10.12 & 0.17 & 9.95 \\
\hline $10: 00$ & $\begin{array}{c}28.8 \\
7\end{array}$ & 4.12 & 2.52 & 1.60 \\
\hline $11: 00$ & $\begin{array}{c}28.8 \\
7\end{array}$ & 3.12 & -1.48 & 4.61 \\
\hline $12: 00$ & $\begin{array}{c}28.8 \\
7 \\
\end{array}$ & 2.12 & 1.30 & 0.81 \\
\hline $13: 00$ & $\begin{array}{c}28.8 \\
7\end{array}$ & 0.12 & 7.628 & -7.50 \\
\hline $14: 00$ & $\begin{array}{c}28.8 \\
9\end{array}$ & 0.10 & 5.64 & -5.54 \\
\hline $15: 00$ & $\begin{array}{c}28.9 \\
1 \\
\end{array}$ & -0.91 & 4.64 & -5.56 \\
\hline $16: 00$ & $\begin{array}{c}28.9 \\
1\end{array}$ & 5.08 & 4.64 & 0.44 \\
\hline $17: 00$ & $\begin{array}{c}28.9 \\
1 \\
\end{array}$ & 3.08 & 6.80 & -3.71 \\
\hline 18:00 & $\begin{array}{c}28.9 \\
1\end{array}$ & 6.08 & 9.80 & -3.72 \\
\hline 19:00 & $\begin{array}{c}28.8 \\
9\end{array}$ & 5.10 & 8.64 & -3.54 \\
\hline
\end{tabular}

4. Menhitung Nilai Remainder

$$
\begin{aligned}
& R_{t}=y_{t}-T_{t}-S_{t} \\
& R_{t}=21-28.875-(-7.67361) \\
& R_{t}=-0.201388889
\end{aligned}
$$

3.3. Data Time series Decompostion Tabel 2. Data Time series Kondisi Cuaca dan Waktu Tempuh 


\begin{tabular}{|c|c|c|c|c|}
\cline { 2 - 5 } $20: 00$ & $\begin{array}{c}28.8 \\
9\end{array}$ & 5.10 & 6.14 & -1.04 \\
\hline $21: 00$ & $\begin{array}{c}28.8 \\
3\end{array}$ & -0.83 & -0.99 & 0.16 \\
\hline $22: 00$ & $\begin{array}{c}28.6 \\
2\end{array}$ & -3.62 & -1.77 & -1.84 \\
\hline $23: 00$ & $\begin{array}{c}28.5 \\
4\end{array}$ & -7.54 & -1.55 & -5.98 \\
\hline $24: 00$ & $\begin{array}{c}28.7 \\
0\end{array}$ & - & -8.65 & 6.94 \\
\hline
\end{tabular}

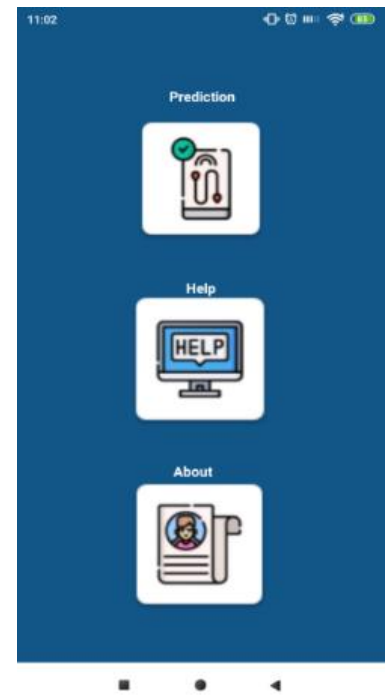

\subsection{Use Case}

Use Case diagram digunakan untuk mengenali proses pada sistem . pada Use Case diagram dapat mengetahui bagaimana user melakukan iteraksi pada aplikasi.

Berikut adalah scenario alur kinerja setiap Use Case pada aplikasi prediksi lalu lintas:

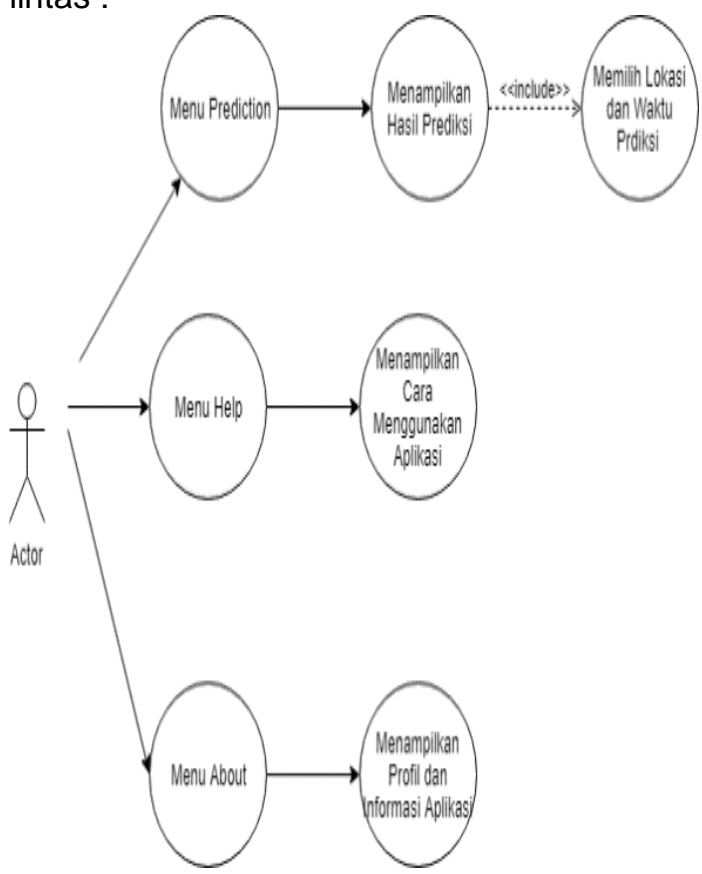

Gambar 2. Use Case Aplikasi Prediksi

\subsection{Implementasi}

prediksi time series decomposition diimplementasikan kedalam program berbasis android.

\section{A. Tampilan Utama}

Pada menu utama aplikasi akan menampilkan 3 menu yaitu Prediction, Help dan About

Gambar 3. Menu Utama Aplikasi Prediksi

\section{B. Menu Tampilan Prediksi}

Menu prediksi aplikasi adalah menu dimana user akan melakukan input waktu dan tujuan untuk melihat prediksi keadaan lalu lintas berdasarkan waktu tempuh

1. Field input untuk Prediksi

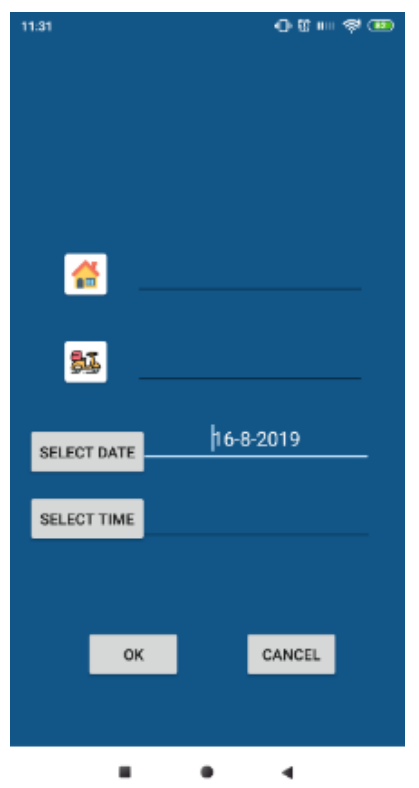

Gambar 4. Menu Field Input Waktu dan Lokasi 
2. Tampilan Select Date

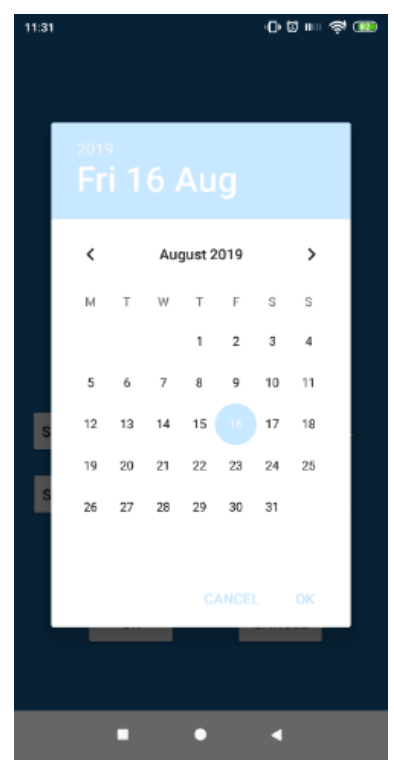

Gambar 5. Tampilan Select Date

3. Tampilan Select Time

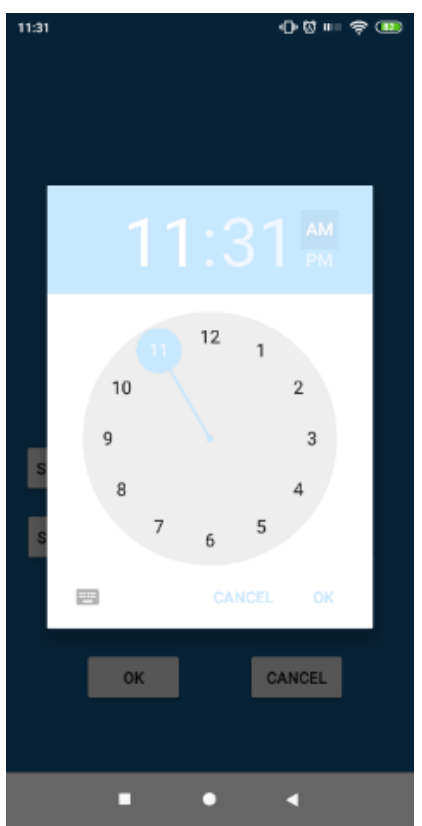

Gambar 6. Tampilan Select Time

\section{Implementasi Menu Hasil Prediksi}

Hasil prediksi akan ditampilkan dalam bentuk waktu tempuh dan cuaca, serta akan ditampilkan pula lokasi dan waktu secara real time.

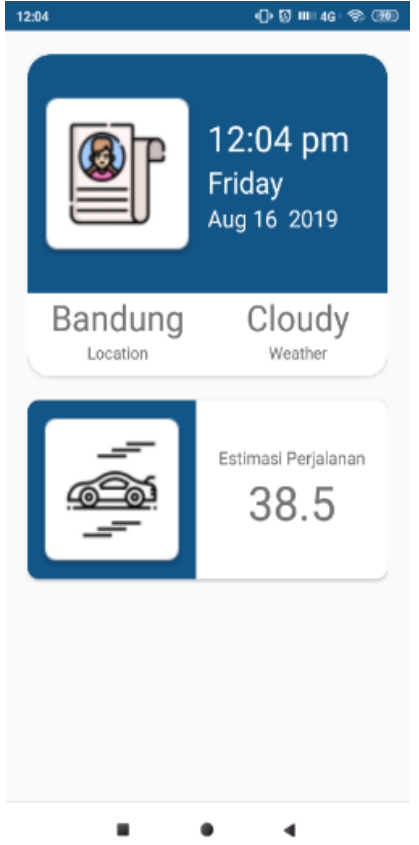

Gambar 7. Tampilan Hasil Prediksi

\section{Implementasi Menu Help}

Menu ini bertujuan untuk memberikan keterangan kepada user mengenai penggunaan aplikasi dan fitur-fitur yang terdapat dalam aplikasi

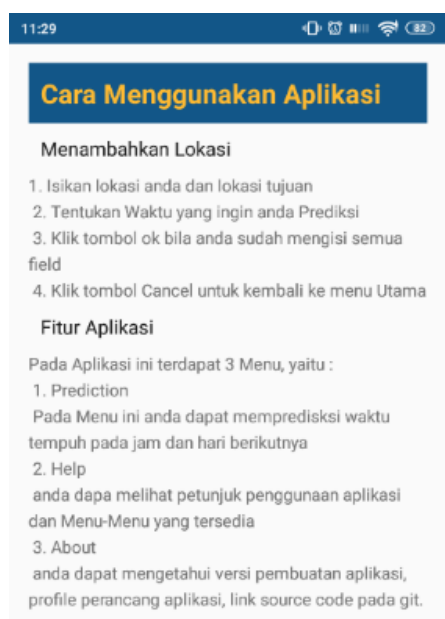

Gambar 8. Tampilan Menu Help 
3.6. Hasil

Tabel 3. Hasil Prediksi

\begin{tabular}{|c|c|c|c|}
\hline Jam & $\begin{array}{l}\text { Kondisi } \\
\text { Cuaca }\end{array}$ & $\begin{array}{c}\text { Wakt } \\
\text { u } \\
\text { temp } \\
\text { uh }\end{array}$ & Prediksi \\
\hline $1: 00$ & Cerah & $\begin{array}{c}21 \\
\text { Menit }\end{array}$ & 21.17 \\
\hline 2:00 & Cerah & $\begin{array}{c}21 \\
\text { Menit }\end{array}$ & 20.45 \\
\hline $3: 00$ & Cerah & $\begin{array}{c}21 \\
\text { Menit }\end{array}$ & 20.54 \\
\hline $4: 00$ & Cerah & $\begin{array}{c}21 \\
\text { Menit }\end{array}$ & 21.5 \\
\hline $5: 00$ & Cerah & $\begin{array}{c}25 \\
\text { Menit }\end{array}$ & 21.68 \\
\hline $6: 00$ & Cerah & $\begin{array}{c}29 \\
\text { Menit }\end{array}$ & 27.6 \\
\hline 7:00 & Cerah & $\begin{array}{c}28 \\
\text { Menit } \\
\end{array}$ & 29.6 \\
\hline 8:00 & Cerah & $\begin{array}{c}36 \\
\text { Menit } \\
\end{array}$ & 29.06 \\
\hline 9:00 & Cerah & $\begin{array}{c}39 \\
\text { Menit } \\
\end{array}$ & 31.43 \\
\hline $\begin{array}{c}10: 0 \\
0\end{array}$ & Cerah & $\begin{array}{c}33 \\
\text { Menit }\end{array}$ & 27.42 \\
\hline $\begin{array}{c}11: 0 \\
0\end{array}$ & Cerah & $\begin{array}{c}32 \\
\text { Menit }\end{array}$ & 27.42 \\
\hline $\begin{array}{c}12: 0 \\
0 \\
\end{array}$ & Cerah & $\begin{array}{c}1 \\
\text { Menit }\end{array}$ & 30.22 \\
\hline $\begin{array}{c}13: 0 \\
0\end{array}$ & Cerah & $\begin{array}{c}29 \\
\text { Menit }\end{array}$ & 35.48 \\
\hline $\begin{array}{c}14: 0 \\
0 \\
\end{array}$ & Cerah & $\begin{array}{c}29 \\
\text { Menit }\end{array}$ & 32.88 \\
\hline $\begin{array}{c}15: 0 \\
0\end{array}$ & Cerah & $\begin{array}{c}28 \\
\text { Menit }\end{array}$ & 33.34 \\
\hline $\begin{array}{c}16: 0 \\
0 \\
\end{array}$ & Cerah & $\begin{array}{c}34 \\
\text { Menit } \\
\end{array}$ & 34.38 \\
\hline $\begin{array}{c}17: 0 \\
0 \\
\end{array}$ & Cerah & $\begin{array}{c}32 \\
\text { Menit }\end{array}$ & 34.04 \\
\hline $\begin{array}{c}18: 0 \\
0\end{array}$ & Cerah & $\begin{array}{c}35 \\
\text { Menit }\end{array}$ & 37.56 \\
\hline $\begin{array}{c}19: 0 \\
0\end{array}$ & Cerah & $\begin{array}{c}34 \\
\text { Menit }\end{array}$ & 36.41 \\
\hline $\begin{array}{c}20: 0 \\
0\end{array}$ & Cerah & $\begin{array}{c}34 \\
\text { Menit }\end{array}$ & 36.41 \\
\hline $\begin{array}{c}21: 0 \\
0 \\
\end{array}$ & Cerah & $\begin{array}{c}28 \\
\text { Menit } \\
\end{array}$ & 27.95 \\
\hline $\begin{array}{c}22: 0 \\
0\end{array}$ & Cerah & $\begin{array}{c}25 \\
\text { Menit }\end{array}$ & 26.88 \\
\hline $\begin{array}{c}23: 0 \\
0\end{array}$ & Cerah & $\begin{array}{c}21 \\
\text { Menit }\end{array}$ & 26.29 \\
\hline $\begin{array}{c}24: 0 \\
0 \\
\end{array}$ & Cerah & $\begin{array}{c}27 \\
\text { Menit }\end{array}$ & 21.18 \\
\hline
\end{tabular}

3.7. RMSE

\begin{tabular}{|c|c|c|c|c|}
\hline Jam & $\begin{array}{c}\text { Kondis } \\
\text { i } \\
\text { Cuaca }\end{array}$ & $\begin{array}{c}\text { Waktu } \\
\text { tempu } \\
\text { h }\end{array}$ & Prediksi & ERROR \\
\hline $1: 00$ & Cerah & $\begin{array}{c}21 \\
\text { Menit }\end{array}$ & 21.17 & -0.17 \\
\hline $2: 00$ & Cerah & $\begin{array}{c}21 \\
\text { Menit }\end{array}$ & 20.45 & 0.55 \\
\hline $3: 00$ & Cerah & $\begin{array}{c}21 \\
\text { Menit }\end{array}$ & 20.54 & 0.46 \\
\hline $4: 00$ & Cerah & $\begin{array}{c}21 \\
\text { Menit }\end{array}$ & 21.5 & -0.5 \\
\hline $5: 00$ & Cerah & $\begin{array}{c}25 \\
\text { Menit }\end{array}$ & 21.68 & 3.32 \\
\hline $6: 00$ & Cerah & $\begin{array}{c}29 \\
\text { Menit }\end{array}$ & 27.6 & 1.4 \\
\hline $7: 00$ & Cerah & $\begin{array}{c}28 \\
\text { Menit }\end{array}$ & 29.6 & -1.6 \\
\hline $8: 00$ & Cerah & $\begin{array}{c}36 \\
\text { Menit }\end{array}$ & 29.06 & 6.94 \\
\hline 9:00 & Cerah & $\begin{array}{c}39 \\
\text { Menit }\end{array}$ & 31.43 & 7.57 \\
\hline $10: 00$ & Cerah & $\begin{array}{c}33 \\
\text { Menit }\end{array}$ & 27.42 & 5.58 \\
\hline $11: 00$ & Cerah & $\begin{array}{c}32 \\
\text { Menit }\end{array}$ & 27.42 & 4.58 \\
\hline $12: 00$ & Cerah & $\begin{array}{c}31 \\
\text { Menit }\end{array}$ & 30.22 & 0.78 \\
\hline $13: 00$ & Cerah & $\begin{array}{c}29 \\
\text { Menit }\end{array}$ & 35.48 & -6.48 \\
\hline $14: 00$ & Cerah & $\begin{array}{c}29 \\
\text { Menit }\end{array}$ & 32.88 & -3.88 \\
\hline $15: 00$ & Cerah & $\begin{array}{c}28 \\
\text { Menit }\end{array}$ & 33.34 & -5.34 \\
\hline $16: 00$ & Cerah & $\begin{array}{c}34 \\
\text { Menit }\end{array}$ & 34.38 & -0.38 \\
\hline $17: 00$ & Cerah & $\begin{array}{c}32 \\
\text { Menit }\end{array}$ & 34.04 & -2.04 \\
\hline $18: 00$ & Cerah & $\begin{array}{c}35 \\
\text { Menit }\end{array}$ & 37.56 & -2.56 \\
\hline $19: 00$ & Cerah & $\begin{array}{c}34 \\
\text { Menit }\end{array}$ & 36.41 & -2.41 \\
\hline $20: 00$ & Cerah & $\begin{array}{c}34 \\
\text { Menit }\end{array}$ & 36.41 & -2.41 \\
\hline $21: 00$ & Cerah & $\begin{array}{c}28 \\
\text { Menit }\end{array}$ & 27.95 & 0.05 \\
\hline $22: 00$ & Cerah & $\begin{array}{c}25 \\
\text { Menit }\end{array}$ & 26.88 & -1.88 \\
\hline $23: 00$ & Cerah & $\begin{array}{c}21 \\
\text { Menit }\end{array}$ & 26.29 & -5.29 \\
\hline 24:00 & Cerah & $\begin{array}{c}27 \\
\text { Menit }\end{array}$ & 21.18 & 5.82 \\
\hline $\begin{array}{c}\text { RMS } \\
\mathrm{E}\end{array}$ & \multicolumn{4}{|c|}{3.8076387} \\
\hline
\end{tabular}

Berdasarkan Tabel di atas dapat dijelaskan bahwa Metode time series decomposition yang digunakan dalam 
memprediksi lalu lintas berdasarkan waktu tempuh dan cuaca dapat memberikan prediksi yang cukup akurat dengan nilai RMSE (Root Mean Square Error) yaitu $3,80 \%$ hasil tersebut membuktikan bahwa dapat digunakan dalam memprediksi lalu lintas berdasarkan waktu tempuh dan kendaraan

\section{Kesimpulan}

Kesimpulan dari penelitian ini sebagai berikut:

1. Metode Time series dengan variable rata-rata waktu tempuh dan kondisi cuaca yang sesuai dapat memprediksi lalu lintasyang cukup akurat.

2. Aplikasi Metode Time series Decomposition berdasarkan waktu tempuh dan kondisi cuaca mampu memberikan prediksi lalulintas sebesar $3.80 \%$ hasil tersebut membuktikan bahwa aplikasi dapat digunakan untuk memprediksi lalu lintas berdasarkan

Saran waktu tempuh dan cuaca

1. Pada penelitian selanjutnya diharapkan data yang digunakan lebih besar dan memliki jangka waktu yang lebih panjang.

2. Pada penelitian selajutnya dapat memasukan variabel kepadatan lalu lintas agar prediksi lalu lintas lebih akurat

3. Dapat menambahkan menu map agar pengguna dapat mengisikan input lokasi dengan menunjuk lokasi yang akan di tempuh

4. Pengembangan kembali aplikasi dapat memprediksi cuaca selain memprediksi waktu tempuh

\section{Referensi}

Aghnaita, F. K. (2016). Peramalan Jumlah Penjualan Tiket Kereta Api Di Stasiun Semarang Poncol Tahun 2016 Menggunakan Metode Dekomposisi. http://lib.unnes.ac.id/26629/

Apostolakis, J. (2009). An introduction to data mining. In Data Mining in Crystallography (pp. 1-35). Springer, Berlin, Heidelberg.

Ashari. (2012). Penerapan Metode Times Series Dalam Simulasi Forecasting Perkembangan Akademik Mahasiswa. Stmikakba, 2(1), 9-16.

Fitria, J. D., Karohmah, N., \& Sunarmi. (2016). Peramalan Jumlah Pasien
DBD Di RSUD Dr. Soeselo Slawi Dengan Metode Dekomposisi Dan Triple Exponential Smoothing Winter's. In Seminar Nasional Pendidikan, Sains dan Teknologi Fakultas Matematika dan IImu Pengetahuan Alam Universitas Muhammadiyah Semarang (pp. 145-152).

Hidayah, N., Purnamasari, I., \& Hayati, M. N. (2017). Penerapan metode fuzzy time series using percentage change. Jurnal Eksponensial, 7(2), 187-192. http://jurnal.fmipa.unmul.ac.id/index.p $\mathrm{hp} /$ exponensial/article/view/67

Julianto, E. N. (2010). Hubungan Antara Kecepatan, Volume Dan Kepadatan Lalu Lintas Ruas Jalan Siliwangi Semarang. Jurnal Teknik Sipil Dan Perencanaan, 12(2), 151-160. https://doi.org/10.15294/jtsp.v12i2.134 8

Mardiati, R. (2014). Studi Tentang Pemodelan Arus Lalu Lintas. Jurusan Teknik Elektro, VIII(2), 177-198.

Metisen, B. M., \& Sari, H. L. (2015). Analisis clustering menggunakan metode $\mathrm{K}$ Means dalam pengelompokkan penjualan produk pada Swalayan Fadhila. Jurnal Media Infotama, 11(2), 110-118.

Ryan, F., \& Wijanarto, W. (2018). Analisis Dan Implementasi Model Peramalan Berbasis Algoritma Moving Avarage Untuk Nilai Tukar Rupiah Terhadap Dolar. Simetris: Jurnal Teknik Mesin, Elektro Dan IImu Komputer, 9(1), 381394.

https://doi.org/10.24176/simet.v9i1.19 97

Safaat, N. (2012). Pemrograman Aplikasi Mobile Smartphone dan Tablet PC Berbasis Android. In Android (Cetakan $\mathrm{Pe})$. Informatika Bandung.

Virrayyani, A., \& Sutikno, S. (2016). Prediksi Penjualan Barang Menggunakan Metode Adaptive Neuro-Fuzzy Inference System (ANFIS). Khazanah Informatika: Jurnal IImu Komputer Dan Informatika, 2(2), 57. https://doi.org/10.23917/khif.v2i2.2554 